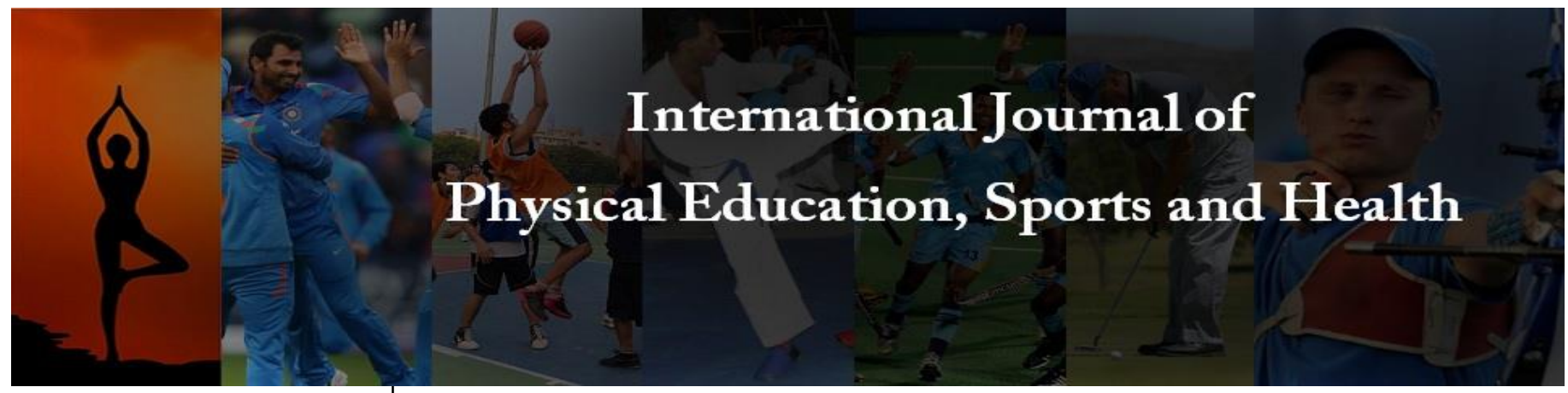

P-ISSN: 2394-1685

E-ISSN: 2394-1693

Impact Factor (ISRA): 5.38

IJPESH 2018; 5(2): 137-142

(C) 2018 IJPESH

www.kheljournal.com

Received: 15-01-2018

Accepted: 16-02-2018

Ajit Dabhokar

School of Physiotherapy,

DY Patil University, Navi

Mumbai, Maharashtra, India

Meherzad Gazdar

School of Physiotherapy,

DY Patil University, Navi

Mumbai, Maharashtra, India

Tejashree Dabholkar

School of Physiotherapy,

DY Patil University, Navi

Mumbai, Maharashtra, India

Vaishnavi Chiddarwar

School of Physiotherapy,

DY Patil University, Navi

Mumbai, Maharashtra, India

Correspondence

Vaishnavi Chiddarwar

School of Physiotherapy,

DY Patil University, Navi

Mumbai, Maharashtra, India

\section{Assessment of upper extremity stability, GIRD (Glenohumeral internal rotation deficit)/GERG (Glenohumeral external rotation gain) ratio and strength of internal rotators (IR) and external rotators (ER) in badminton players}

\author{
Ajit Dabhokar, Meherzad Gazdar, Tejashree Dabholkar and Vaishnavi \\ Chiddarwar
}

Abstract

Racquet sports have gained increasing popularity in Asia. In the current study performed on 25 district level male badminton players aging between 18-25 years assessment of GIRD/GERG ratio, strength of internal, external rotators and of upper extremity stability was done on the dominant and non-dominant side. On statistical analysis using paired t-test.The internal and external rotators were stronger on dominant side when compared to the non-dominant side. The internal rotators were stronger than the external rotators on both dominant and non-dominant side. The external rotation range of motion was more than the internal range of motion on the dominant and non-dominant side. GIRD/GERG ratio was significant in badminton players $(p>0.0001)$. Correlational statistics using Spearman's test showed that the strength of the dominant side external rotators correlated with the CKCUEST.The strength of the non-dominant side external rotators, both side internal rotators and GIRD/GERG ratio did not have any significant correlation with the CKCUEST.

Keywords: Badminton, glenohumeral rotation, closed kinematic chain upper extremity stability

\section{Introduction}

The Glenohumeral joint is inherently an unstable joint based solely on bony configurations. Stability of this joint is mostly maintained by the ligaments and musculotendinous units ${ }^{[1]}$. Buckley and Kerwin reported that the angular velocities of badminton smash, tennis or volleyball serve, and baseball pitch are all within a small range, thus the physiological demands on the shoulder of these sports are very similar ${ }^{[2]}$.

Different overhead sports show different characteristics but have similar movement patterns. In each of these overhead sports, the dominant upper limb is subjected to repetitive overhead movements ${ }^{[3,4]}$.

The mechanics of an overhead stroke or serve in racquet sports are very similar to that of an overhead throw ${ }^{[5]}$ the shoulder has to be lax enough to allow the extra degrees of external rotation necessary for an adequate serve and at the same time has to be stable enough to prevent any subluxations. This delicate balance between mobility and stability is referred to as 'thrower's paradox' ${ }^{[4]}$ and if compromised, can lead to injury ${ }^{[6]}$.

Racquet sports, especially lawn tennis and badminton have been gaining popularity in Asian countries like India. With this increase in popularity, the injury rate in the sport has also increased ${ }^{[7]}$.

Sports that involve repetitive overarm motions like baseball, badminton, and tennis require well co-ordinated and synchronized actions of the shoulder muscles, in particular, the rotators ${ }^{[8]}$.

Badminton is a sport that requires a lot of overhead shoulder motion, with the shoulder in abduction/external rotation ${ }^{[9]}$.

Studies have shown a significant difference in the glenohumeral internal rotation range of motion between dominant and non-dominant shoulders of overhead sport players ${ }^{[3,4,10-15]}$. 
This is defined as 'Gleno-humeral internal rotation deficit' (GIRD), which is the loss in degrees of the gleno-humeral internal rotation of the throwing shoulder compared with the non-throwing shoulder ${ }^{[15]}$. An accepted level of GIRD is less than $20^{\circ}$ deficit of glenohumeral internal rotation or less than $10 \%$ deficit of the total rotation seen in throwing shoulder as compared to the non-throwing shoulder ${ }^{[15]}$.

This may also be compared with GERG (glenohumeral external rotation gain). If the GIRD/GERG ratio is greater than 1, the patient will probably develop shoulder problems. ${ }^{16}$ Gowitzke and Waddel reported that during the badminton forehand smash, elbow extension ends before impact and the power at impact comes mainly from the shoulder ${ }^{[17]}$.

Hutchinson [18] stated that the repetitive and forceful movements in overhead sports render the shoulder vulnerability to injuries. Extreme difference in strength between the prime movers (agonists) and antagonist muscle groups in the shoulder has been reported to be associated with the rate of injury in this joint ${ }^{[19]}$

Commonly, the musculoskeletal physical exam is focused on measures of range of motion (ROM) and muscular strength of the affected segment that could not provide enough information about overall segment functional level of activity ${ }^{[20]}$. Thus, shoulder evaluation could be improved by including techniques that assess functional movements and biomechanical impairment present in professional or daily life activities ${ }^{[20]}$. Functional tests could be considered a valuable complementary low-cost clinical tool to provide quantitative data about the functional ability and performance of a body segment $[21,22]$. The closed-kinetic chain upper extremity stability test (CKCUEST) is intended for these purposes.

In overhead sports however, shoulder motion uses synchronous concentric contraction of the agonist and eccentric contraction of the antagonist ${ }^{[23,24]}$. It is essential that appropriate eccentric action of the antagonist throughout the range of movement to facilitate smooth and safe shoulder movements guard the forceful concentric action of agonist ${ }^{[25]}$. Common strength deficits demonstrated by throwing athletes are weak shoulder external rotators and strong shoulder internal rotators and adductors. Unilateral muscle ratio of agonist and antagonist muscle is used for assessment of muscle balance necessary for dynamic stabilization. The important muscle strength ratios which need are the external/internal rotation muscle ratio and the scapular protractor/retractor and elevator/depressor muscle ratio. These muscle groups have shown the greatest muscle activity in EMG studies during all phases of throwing and contribute to mobility and stability of both the humerus and scapula ${ }^{[26]}$.

Thus, the aim of our study is to assess the upper extremity stability, GIRD/GERG ratio and strength ratio of IR and ER in badminton players.

\section{Materials and methods}

\subsection{Material}

- Push and Pull Dynamometer

- Universal Goniometer

- Weighing scale

- Stadiometer

- Velcro straps

- Stopwatch

- Data recording sheet- Proforma

- Pencil and pen

- Consent form
1. Institutional ethics committee approval was taken, subject's consent was taken

Research design - Cross sectional study

2. Sample size -25 male subjects

3. Study subjects -Inclusion criteria - District level badminton players

Exclusion criteria -Subjects having any musculoskeletal problems, injuries (fractures, dislocations), surgeries in shoulder, elbow, forearm, wrist and hand.

Any history of inflammatory joint disease, neurological disorder, or injury to upper extremity.

Tightness, deformities or contractures of the upper extremity. Associates musculoskeletal abnormalities in shoulder, wrist and hand.

\subsection{Methodology}

All the details of the subjects were recorded including age, height, weight, occupation, hand dominance. Medical history was asked to scrutinize the subjects who came under exclusion criteria.

Prior to the commencement of data collection, the subjects were asked to fill the consent form.

Subjects were told about the closed kinetic chain upper extremity stability test. They were given detailed explanation regarding how to perform it.

Subjects were told that their ranges of shoulder internal and external rotations will be assessed with goniometer.

A push pull dynamometer was used to measure the strength of shoulder rotators of 25 subjects in the age group of 18-25 years.

The procedures for conducting the tests are as follows.

Procedure for the assessment of closed kinetic chain upper extremity stability test ${ }^{[27]}$.

Two strips of athletic tape with a width of 1.5 inches were placed parallel to each other 36 inches apart on a tile floor as measured with a standard measuring tape.

The starting position for the test was one hand on each piece of tape while assuming a pushup position.

The subjects were instructed that from the starting position they were to use one hand to reach across their body and touch the piece of tape lying under the opposing hand. After touching the tape line, the hand would be returned to the original starting position. The subject would perform the same movement with the other hand.

Touches were counted as every time the hand reached across the subject's body and touched the tape. The total time for the trial was 20 seconds.

Each subject performed a warm up trial and then three real trials of the test with a rest period of 45 seconds between trials. An average of the three trials was used for data analysis.

Procedure for the assessment of internal and external rotation range ${ }^{[28]}$.

A goniometer was used to measure the range of external and internal rotation.

Testing position- Subject in supine position, with the arm being tested in $90^{\circ}$ of shoulder abduction. Forearm placed perpendicular to the supporting surface and in $0^{\circ}$ of supination and pronation so that the palm of the hand faces the feet. Resting the full length of humerus on the examining table. The elbow was not supported by the examining table. A pad was placed under the humerus so that the humerus was in level with the acromion process. 
Goniometer Alignment- Centre fulcrum of the goniometer over the olecranon process. Proximal arm aligned either parallel to or perpendicular to the floor, distal arm aligned with the ulna, using olecranon process and ulnar styloid as reference.

Testing motion: For medial rotation- Medially rotate the shoulder by moving the forearm anteriorly, bringing the palm of the hand towards the floor. Maintain the shoulder in $90^{\circ}$ of abduction and the elbow in $90^{\circ}$ of flexion during motion.

For lateral rotation- Rotate the shoulder laterally by moving the forearm posteriorly, bringing the dorsal surface of the palm of the hand towards the floor. Maintain the shoulder in $90^{\circ}$ of abduction and the elbow in $90^{\circ}$ of flexion during motion. Three readings were taken for each motion on both the sides and the average was calculated.

Procedure for the assessment of shoulder internal and external rotation strength: Testing was performed using a push pull dynamometer for both dominant and non-dominant shoulders. Each subject was seated with the shoulder in $90^{\circ}$ of abduction and the elbow flexed to $90^{\circ}$ (parallel to the horizontal plane). This position defined neutral rotation $\left(0^{\circ}\right)$. Strength was tested through $110^{\circ}$ of motion, between $20^{\circ}$ of medial rotation from neutral, and $90^{\circ}$ of lateral rotation from neutral. The upper body was stabilized with a strap placed horizontally across the chest and under the axilla. After proper positioning, the subject was instructed in the testing sequence and performed 3 maximal repetition. The instructions given to the subjects were as follows, "The instrument given is used to measure the strength of your grip. You need to press it as hard as you can with and hold it for 5 seconds". All participants were tested in medial rotation first. Medial rotation strength was tested in a range from $90^{\circ}$ of lateral rotation to $20^{\circ}$ of medial rotation. Testing was initiated with the arm in $90^{\circ}$ of lateral rotation with alternate concentric medial rotation testing followed by eccentric medial rotation testing. Lateral rotation strength was tested from $20^{\circ}$ of medial rotation to $90^{\circ}$ of lateral rotation. Testing was initiated with the arm in $20^{\circ}$ of medial rotation with alternate concentric lateral rotation testing followed by eccentric lateral rotation testing. Gravity correction was not performed. Shoulders were tested on an alternating basis (i.e., the first subject's right arm was tested first, then his left; the next subject's left arm first, then right) to limit effects from order.

The data thus obtained was statistically analyzed with respect to the objectives.

\section{Results \& Discussion}

\subsection{Tables and Figures (Results)}

Table 1: Demographic Characteristics

\begin{tabular}{|c|c|}
\hline & Mean \pm SD \\
\hline Age $($ Yrs $)$ & $24.08 \pm 3.53$ \\
\hline Height $(\mathrm{Cm})$ & $176.36 \pm 2.44$ \\
\hline Weight $(\mathrm{Kg})$ & $72.64 \pm 4.85$ \\
\hline
\end{tabular}

Table 2: Comparison of Strength of Internal Rotators on Dominant and Non-dominant side

\begin{tabular}{|c|c|c|c|}
\hline & $\begin{array}{c}\text { Dominant } \\
\text { Internal Rotators }\end{array}$ & $\begin{array}{c}\text { Non- Dominant } \\
\text { Internal Rotators }\end{array}$ & P value \\
\cline { 1 - 3 } Mean & 11.56 & 10.16 & \multirow{2}{*}{$0.0215^{*} \mathrm{~S}$} \\
\hline SD & 2.00 & 1.67 & \\
\hline
\end{tabular}

Table 3: Comparison of Strength of External Rotators on Dominant and Non-dominant side

\begin{tabular}{|c|c|c|c|}
\hline & $\begin{array}{c}\text { Dominant } \\
\text { External Rotators }\end{array}$ & $\begin{array}{c}\text { Non-Dominant } \\
\text { External Rotators }\end{array}$ & P value \\
\hline Mean & 11.44 & 10.04 & $<$ \\
SD & 2.00 & 2.01 & $0.0001 * \mathrm{ES}$ \\
\hline
\end{tabular}

Table 4: Comparison of Range of Motion of Rotations on dominant side

\begin{tabular}{|c|c|c|c|}
\hline & Right IR & Right ER & P value \\
\cline { 1 - 3 } Mean & 88.40 & 95.00 & \multirow{2}{*}{$0.0002 * \mathrm{ES}$} \\
\hline SD & 2.78 & 7.63 & \\
\hline
\end{tabular}

Table 5: Comparison of Range of Motion of Rotations on Nondominant side

\begin{tabular}{|c|c|c|c|}
\hline & Left IR & Left ER & P value \\
\hline Mean & 85.00 & 87.40 & \multirow{2}{*}{0.0505 NS } \\
\hline SD & 3.53 & 5.97 & \\
\hline
\end{tabular}

Table 6: Comparison between GIRD and GERG

\begin{tabular}{|c|c|c|c|}
\hline & GIRD & GERG & P value \\
\hline Mean & 3.80 & 7.60 & \multirow{2}{*}{$<0.0001 \mathrm{ES}$} \\
\hline SD & 3.31 & 3.85 & \\
\hline
\end{tabular}

\section{Correlational Statistics}

Table 7: Correlation between CKCUEST and Dominant Side External Rotators

\begin{tabular}{|l|l|}
\hline Spearman $r=0.6741$ & 0.0002 ES \\
\hline
\end{tabular}

Table 8: Correlation between CKCUEST and Dominant Side Internal Rotators

\begin{tabular}{|l|l|} 
Spearman $r=0.01417$ & $0.9476 \mathrm{NS}$ \\
\hline
\end{tabular}

Table 9: Correlation between CKCUEST and Non-Dominant Side External Rotators

\begin{tabular}{|l|l|}
\hline Spearman $r=0.1795$ & $0.4014 \mathrm{NS}$ \\
\hline
\end{tabular}

Table 10: Correlation between CKCUEST and Non-Dominant Side Internal Rotators

$$
\begin{array}{|l|l|}
\hline \text { Spearman } r=-0.1039 & 0.6291 \mathrm{NS} \\
\hline
\end{array}
$$

Table 11: Correlation between CKCUEST and GIRD/GERG Ratio

\begin{tabular}{|l|l|}
\hline Spearman $r=-0.1132$ & $0.5985 \mathrm{NS}$ \\
\hline
\end{tabular}

\subsection{Discussion}

In our study an effort was made to assess closed kinetic chain upper extremity stability test, GIRD/GERG ratio and the strength ratio of shoulder internal and external rotators in badminton players.

In the study all the 25 subjects were male and right hand dominant badminton players.

Average Age of the subjects was 24.08 years, average height was $176.36 \mathrm{~cm}$ and weight was $72.64 \mathrm{~kg}$ as seen from the Table no. 1.

From Table no. 2 it is seen that the dominant internal rotators average strength is more (11.56) than the non-dominant internal rotators $(10.16)$ with a $\mathrm{P}$ value of 0.0215 .

From Table no. 3 it is seen that the dominant external rotators average strength (11.44) is more than the non-dominant external rotators (10.04), with significant $P$ value of $<0.0001$. From Table no. $2 \& 3$, it is seen that the internal rotators are 
stronger than the external rotators on both dominant and nondominant side.

In the badminton players it is seen that the shoulder rotators of the dominant side are stronger as they constantly use the dominant hand for servicing and smashing while the nondominant hand is comparatively at rest. So even though the players train themselves bilaterally the discrepancy is the strength of the dominant and non-dominant side shoulder rotators exists because of the nature of the game.

Significantly higher concentric work is demonstrated in the IR of the dominant side than the non-dominant in the range corresponding to the deceleration phase. The reason for higher concentric IR work output in the range of motion corresponding to the deceleration phase could be due to the training effect of smashing in badminton. The smashing action takes place in the acceleration phase ${ }^{[25]}$.

Fleisig [31] stated that late cocking is a critical moment in overhead sports because the shoulder is in full external rotation and subjected to maximum anterior and superior forces. In the late cocking phase, maximal electromyographic (EMG) activities of the external rotators (ER) have been recorded ${ }^{[32,33]}$. The internal rotators (IR) have also been reported to work in this to prevent excessive external rotation of the humerus ${ }^{[23,32,34]}$. because the arm is brought to stop within a short period of time following very high angular velocities, high eccentric force must be produced in the ER, which could predispose the muscles to tensile failure ${ }^{[31]}$.

During the cocking phase, the movement of shoulder external rotation is accelerated until the final $30^{\circ}$ of movement where it starts to decelerate ${ }^{[35,36]}$, in preparation for the shoulder to perform smashing. This deceleration happens in a short period of time, and the IR must develop high force over a small range of motion. Besides controlling the arm movement, we believe that the IR perform a large amount of negative work to check the movement of external rotation in late cocking and to provide protection against excessive anterior stress to the glenohumeral joint ${ }^{[25]}$.

Table no. 4 shows average ranges of rotation on the dominant side with average external rotation (95.00) more than the internal rotation (88.40) with a significant $P$ value of 0.0002 .

Table no. 5 shows average ranges of rotation on the nondominant side with average external rotation (87.40) more than the internal rotation $(85.00)$ with an insignificant $\mathrm{P}$ value $(0.0505)$

Table no. 6 shows average GIRD as 3.80 and GERG as 7.60 with a significant $\mathrm{P}$ value $<0.0001$.

In the badminton players the dominant side shoulder rotators are not only seen to be stronger but also the range of motion of the dominant side shoulder rotators is seen to be more that the non-dominant side, with external rotation range increased more than the internal rotation range.

Numerous articles have consistently shown that the dominant shoulder in overhead athletes exhibits an increase of external rotation and a co-existing decrease in internal rotation. However, if you take the total rotation motion and combine ER and IR measurements the numbers are almost identical.

Because of this difference in the internal and external rotation range between the dominant and non-dominant side which is also seen from the above results.

Results of the present study also show significant reduction in the internal rotation and extension ROM and a gain in the external rotation of the dominant shoulder compared to the non-dominant shoulder of racquet players ${ }^{[7]}$. Also, there was a significant reduction in internal rotation, extension and adduction and an increase in external rotation of the dominant shoulder of racquet players when compared to dominant shoulder of non-racquet players ${ }^{[7]}$. During the follow through phase of an overhead motion, the shoulder joint is subjected to distractive forces of up to $750 \mathrm{~N}$ which is mainly resisted by the postero-inferior capsule ${ }^{[15,37]}$. With repetitive loading, the posterior capsule is said to undergo micro trauma causing hypertrophy and increased fibroblastic activity during the healing process, leading to contracture and thickening of the capsule $[3,39]$. This reduces the capsular pliability causing restriction of internal rotation, extension and horizontal adduction ${ }^{[3,37,39]}$.

Also, it is seen that overhand throwing places high loads and stresses on the joints and tissues of the shoulder and arm. As a result, throwing athletes regularly demonstrate altered shoulder internal and external ranges of motion where internal rotation (IR) is decreased and external rotation is increased in the dominant arm when compared with the nondominant arm. This alteration can exist as a result of alterations to the bones (humeral retroversion), capsule (posterior thickening), or muscle (passive stiffness known as thixotropy)._When the amount of IR or total arc of motion difference reaches a certain threshold (typically 20 or more degrees of IR or 8 degrees total arc difference), it is known as glenohumeral internal rotation deficit or total arc of motion deficit. Glenohumeral internal rotation deficit and total arc of motion deficit can cause alterations in biomechanics such as scapular "wind-up" or alteration of glenohumeral joint kinematics, which can in turn lead to clinical findings of impingement and labral pathology ${ }^{[40]}$

Table no. 7 shows the correlation between the CKCUEST and the dominant side external rotators with an extremely significant $p$ value of 0.0002 and Spearman $r$ of 0.6741 .

Table no. 8 shows the correlation between the CKCUEST and the dominant side internal rotators with non-significant $\mathrm{p}$ value of 0.9476 and Spearman $r$ of 0.01417 .

Table no. 9 shows the correlation between the CKCUEST and the non-dominant side external rotators with a non-significant $\mathrm{p}$ value of 0.4014 and Spearman $\mathrm{r}$ of 0.719 .

Table no. 10 shows the correlation between the CKCUEST and the non-dominant side internal rotators with nonsignificant $p$ value of 0.6291 and Spearman $r$ of -0.1039 .

Table no. 11 shows the correlation between the CKCUEST and the GIRD/GERG ratio with non-significant $p$ value of 0.5985 and Spearman $r$ of -0.1132 .

From our study it is thus seen that there is a correlation between the CKCUEST and the dominant side external rotators. External rotators stabilize the shoulder and thus their strength could be correlated with the CKCUEST

For performing a closed kinetic upper extremity test apart from shoulder strength, the core and leg muscle strength is also important to maintain the push up position.

Thus, the non-dominant side rotators strength does not seem to be correlated with the CKCUEST.

\section{Conclusions}

The current study concluded the following:

i) The internal and external rotators are stronger on the dominant side when compared to the non-dominant side.

ii) The internal rotators are stronger than the external rotators on the dominant as well as on the non-dominant side.

iii) The external rotation range of motion was greater than the internal rotation range of motion on the dominant as well as on the non-dominant side.

iv) GIRD/GERG ratio was significant in badminton players. 
v) Strength of dominant side external rotators correlated with CKCUEST.

vi) The strength of non-dominant side external rotators, both side internal rotators and GIRD/GERG ratio had no significant correlation with CKCUEST.

5. Acknowledgments: The authors thank Dr.Unnati PanditDirector of DY Patil School of Physiotherapy for her cooperation and support to the study.

\section{Conflict of interest: Nil}

\section{Funding: None.}

\section{References}

1. Job CM. Gross anatomy of the shoulder. In: Rockwood CA, Matsen FA, eds. The Shoulder. Philadelphia, PA: Saunders Company, 1998, 34-97

2. Buckley JP, Kerwin DG. The role of the biceps and triceps brachii during tennis serving. Ergonomics. 1988; 31:1621-1629.

3. Torres RR, Gomes JL. Measurement of glenohumeral internal rotation in asymptomatic tennis players and swimmers. Am J Sports Med. 2009; 37(5):1017-23. doi: 10.1177/0363546508329544. [PubMed] [Cross Ref]

4. Wilk KE, Meister K, Andrews JR. Current concepts in the rehabilitation of the over-head throwing athlete. Am J Sports Med. 2002; 30:131-51. [PubMed]

5. Craig A. The shoulder complex. In: Maria Z, Christopher B, John C, editors. Sports Physiotherapy: Applied Science and Practice. Churchill Livingstone, 1995.

6. Downar JM, Sauers EL. Clinical Measures of Shoulder Mobility in the Professional Baseball Player. J Athl Train. 2005; 40(1):23-9. [PMC free article] [PubMed]

7. Apurv Shimpi P, Shah Bhakti, Karnik Roshni, Savita Rairikar A, Ashok Shyam, Parag Sancheti K. Scapular Resting Position and Gleno-Humeral Movement Dysfunction in Asymptomatic Racquet Players: A CaseControl Study. Asian J Sports Med. 2015; 6(4):e24053.

8. Dysfunction in Asymptomatic Racquet Players: A CaseControl Study. Asian J Sports Med. 2015; 6(4):e24053.

9. Ellenbecker TS. Shoulder internal and external rotation strength and range of motion of highly skilled junior tennis players. Isokinet Exerc Sci. 1992; 2:65-72.

10. Manit Arora, Sunil Shetty H, Ravindra Khedekar G, Sachin Kale. a Conjoint Associate Lecturer, St. George Clinical School, University of New South Wales, Sydney, Australia b Department of Orthopedics, Padmashree Dr D.Y. Patil Hospital and Research Centre, Navi Mumbai, India. Over half of badminton players suffer from shoulder pain: Is impingement to blame? Journal of arthroscopy and joint surgery. 2015; 2:33 e3 6.

11. Bigliani LU, Codd TP, Connor PM, Levine WN, Littlefield MA, Hershon SJ. Shoulder motion and laxity in the professional baseball player. Am J Sports Med. 1997; 25(5):609-13. [PubMed]

12. Borsa PA, Wilk KE, Jacobson JA, Scibek JS, Dover GC, Reinold MM et al. Correlation of range of motion and glenohumeral translation in professional baseball pitchers. Am J Sports Med. 2005; 33(9):1392-9. doi: 10.1177/0363546504273490. [PubMed] [Cross Ref]

13. Crockett HC, Gross LB, Wilk KE, Schwartz ML, Reed J, O'Mara $\mathrm{J}$ et al. Osseous adaptation and range of motion at the glenohumeral joint in professional baseball pitchers. Am J Sports Med. 2002; 30(1):20-6. [PubMed]
14. Johnson L. Patterns of shoulder flexibility among college baseball players. J Athl Train. 1992; 27(1):44-9. [PMC free article] [PubMed]

15. Meister $K$. Injuries to the shoulder in the throwing athlete. Part one:

Biomechanics/pathophysiology/classification of injury. Am J Sports Med. 2000; 28(2):265-75. [PubMed]

16. Burkhart SS, Morgan CD, Kibler WB. The disabled throwing shoulder: spectrum of pathology Part I: pathoanatomy and biomechanics. Arthroscopy. 2003; 19(4):404-20. doi: 10.1053/jars.2003.50128. [PubMed] [Cross Ref]

17. Chapter 5 Shoulder. Page No. 253. David J. Magee. Orthopedic Physical Assessment. Fifth edition.

18. Gowitzke BA, Waddell DB. Biomechanical studies of badminton overhead power strokes. A review. 9th International Symposium of the International Society of Biomechanics in Sports. Iowa State University, Ames, IA; 1991, 267-272.

19. Hutchinson MR, Laprade RF, Burnett QM, Moss R, Terpstra J. Injury surveillance at the USTA Boys' Tennis Championships: a 6-yr study. Med Sci Sports Exerc. 1995; 27:826-830.

20. Ellenbecker TS. A total arm strength isokinetic profile of highly skilled tennis players Isokinetic Exerc Sci 1991: 1:9-22.

21. Schulte-Edelmann JA, Davies GJ, Kernozek TW, Gerberding ED. The effects of plyometric training of the posterior shoulder and elbow. J Strength Cond Res. 2005; 19(1):129-134. [PubMed]

22. Goldbeck TG, Davies CJ. Test-retest reliability of the closed kinetic chain upper extremity stability test: a clinical field test. Sport Rehabil. 2000; 9:35-45.

23. Roush JR, Kitamura J, Waits MC. Reference values for the closed kinetic chain upper extremity stability test (CKCUEST) for collegiate baseball players. N Am J Sports Phys Ther. 2007; 2(3):159-163. [PMC free article] [PubMed]

24. Gowan ID, Jobe FW, Tibone JE, Perry J, Moynes DR. A comparative electromyographic analysis of the shoulder during pitching. Professional versus amateur pitchers. Am J Sports Med. 1987; 15:586-59.

25. Ryu RK, McCormick J, Jobe FW, Moynes DR, Antonelli DJ. An electromyographic analysis of shoulder function in tennis players. Am J Sports Med. 1988; 16:481-485.

26. Gabriel YF, Ng PT, Patrick CW, Lam PT. Study. A Study of Antagonist/Agonist Isokinetic Work Ratios of Shoulder Rotators in Men Who Play Badminton. J Orthop Sports Phys Ther. 2002; 32:399-404.

27. Wilk et al. Shoulder Injuries in the Overhead Athlete. J Orthop Sports Phys Ther. 2009; 39(2):38-54. Article.

28. James R, Roush PT ATC, Jared Kitamura PT DPT. Michael Chad Waitsc Reference Values for the Closed Kinetic Chain Upper Extremity Stability Test (CKCUEST) for Collegiate Baseball Players. N Am J Sports Phys Ther. 2007; 2(3):159-163.

29. Cynthia C, Norkins Pamela K. Levangie. Chapter 4 shoulder. Joint structure and function A Comprehensive Analysis, 74-81.

30. Helga Tatiana Tucci, Jaqueline Martins, Guilherme de Carvalho Sposito, Paula Maria Ferreira Camarini, Anamaria Siriani de Oliveira. Closed Kinetic Chain Upper Extremity Stability test (CKCUES test): A reliability study in persons with and without shoulder impingement syndrome. BMC Musculoskelet Disord. 
2014; 15:1.

31. Yildiz Y, Aydin T, Sekir U, Kiralp MZ, Hazneci B, Kalyon TA. Shoulder terminal range eccentric antagonist/concentric agonist strength ratios in overhead athletes. Scand J Med Sci Sports. 20006; 16:174-180.

32. Fleisig GS, Andrews JR, Dillman CJ, Escamilla RF. Kinetics of baseball pitching with implications about injury mechanisms. Am J Sports Med. 1995; 23:233-239.

33. Bramhall JP. Functional anatomy of the shoulder. In: Andrews JR, Zarins B, Wilk KE, eds. Injuries in Baseball. Philadelphia, PA: Lippincott-Raven, 1998: 3945.

34. Jobe FW, Tibone JE, Perry J, Moynes D. An EMG analysis of the shoulder in throwing and pitching. A preliminary report. Am J Sports Med. 1983; 11:3-5

35. Glousman R, Jobe F, Tibone J, Moynes D, Antonelli D, Perry J. Dynamic electromyographic analysis of the throwing shoulder with glenohumeral instability. J Bone Joint Surg Am. 1988; 70:220-226.

36. Dillman CJ, Fleisig GS, Andrew JR. Biomechanics of pitching with emphasis upon shoulder kinematics. J Orthop Sports Phys Ther. 1993; 18:402-408.

37. Dillman CJ, Fleisig GS, Andrew JR. Mechanics of throwing. In: Hawkins RJ, Misamore GW, eds. Shoulder Injuries in the Athlete: Surgical Repair and Rehabilitation. New York, NY: Churchill Livingstone, 1996, 23-30.

38. van der Hoeven $\mathrm{H}$, Kibler WB. Shoulder injuries in tennis players. Br J Sports Med. 2006; 40(5):435-40. doi: 10.1136/bjsm.2005.023218. discussion 440. [PMC free article] [PubMed] [Cross Ref]

39. Thomas SJ, Swanik KA, Swanik CB, Kelly JD. Internal rotation and scapular position differences: a comparison of collegiate and high school baseball players. J Athl Train. 2010; 45(1):44-50. doi: 10.4085/1062-605045.1.44. [PMC free article] [PubMed] [Cross Ref]

40. Kibler WB, Sciascia A, Thomas SJ. Glenohumeral internal rotation deficit: pathogenesis and response to acute throwing. Sports Med Arthrosc. 2012; 20(1):34-8. 